\title{
Solubilization of beclomethasone dipropionate in sterically stabilized phospholipid nanomicelles (SSMs): physicochemical and in vitro evaluations
}

This article was published in the following Dove Press journal:

Drug Design, Development and Therapy

16 February 2012

Number of times this article has been viewed

\section{Mohanad Naji Sahib \\ Shaymaa Abdalwahed \\ Abdulameer \\ Yusrida Darwis \\ Kok Khiang Peh \\ Yvonne Tze Fung Tan}

School of Pharmaceutical Sciences, Universiti Sains Malaysia, Penang, Malaysia
Correspondence: Mohanad Naji Sahib School of Pharmaceutical Sciences, Universiti Sains Malaysia, I 1800 Minden, Penang, Malaysia

Tel +6 0164897348

Fax +6 046570017

Emailmohanad_pharm@yahoo.com
Background: The local treatment of lung disorders such as asthma and chronic obstructive pulmonary disease via pulmonary drug delivery offers many advantages over oral or intravenous routes of administration. This is because direct deposition of a drug at the diseased site increases local drug concentrations, which improves the pulmonary receptor occupancy and reduces the overall dose required, therefore reducing the side effects that result from high drug doses. From a clinical point of view, although jet nebulizers have been used for aerosol delivery of water-soluble compounds and micronized suspensions, their use with hydrophobic drugs has been inadequate.

Aim: To evaluate the feasibility of sterically stabilized phospholipid nanomicelles (SSMs) loaded with beclomethasone dipropionate (BDP) as a carrier for pulmonary delivery.

Methods: 1,2-Distearoyl-sn-glycero-3-phosphoethanolamine-N-methoxy-poly(ethylene glycol 5000) polymeric micelles containing BDP (BDP-SSMs) were prepared by the coprecipitation and reconstitution method, and the physicochemical and in vitro characteristics of BDP-SSMs were investigated.

Results: BDP-SSMs were successfully prepared with a content uniformity and reproducibility suitable for pulmonary administration. The maximum solubility of BDP in SSMs was approximately 1300 times its actual solubility. The particle size and zeta potential of BDP-SSMs were $19.89 \pm 0.67 \mathrm{~nm}$ and $-28.03 \pm 2.05 \mathrm{mV}$, respectively. The SSMs system slowed down the release of BDP and all of the aerodynamic values of the aerosolized rehydrated BDP-SSMs were not only acceptable but indicated a significant level of deposition in the lungs.

Conclusion: The SSM system might be an effective way of improving the therapeutic index of nebulized, poorly soluble corticosteroids.

Keywords: beclomethasone, PEGylated polymer, aerodynamic, in vitro dissolution

\section{Introduction}

In pharmaceutical technology, many drug-releasing and drug-targeting systems have been developed to reduce drug degradation and/or enhance the amount of drug in the target area. ${ }^{1,2}$ In general, poorly water-soluble agents are usually associated with poor absorption and bioavailability. ${ }^{3}$ In addition, from a pharmacological point of view, hydrophobicity is beneficial for the drug-tissue relationship but formulation, solubilization, and stabilization of these agents are problems that should be investigated. ${ }^{4}$ Accordingly, many pharmaceutical delivery systems from polymeric micelles have been introduced recently due to their potential ability to solubilize poorly soluble drugs and to form small particle sizes $(<100 \mathrm{~nm})$ by which they evade phagocytosis. . $^{1,5}$ 
Polymeric micelle so-called colloidal dispersions are selfassembled core-shell nanostructures formed in an aqueous solution consisting of hydrophobic fragments of amphiphilic molecules forming the core of a micelle, which is segregated from the environment by hydrophilic parts of the molecules that form the micelle corona. ${ }^{6,7}$ Cargo space (core) formed from the hydrophobic segment solubilizes a variety of poorly soluble therapeutic and diagnostic agents. This solubilization increases the bioavailability and circulation time after parenteral administration, as well as modifying the pharmacokinetics and biodistribution of the therapeutic agents. ${ }^{1,8}$ The small size of the micelles permits their extravasation and accumulation in a variety of pathological sites such as tumors. ${ }^{4}$ Additionally, polymeric micelles are easily prepared on a large scale. ${ }^{8}$

Polymeric micelles are more stable than micelles prepared from conventional detergents and some amphiphilic copolymers have critical micelle concentration values as low as $10^{-6} \mathrm{M} \cdot{ }^{9,10}$ This is especially important from a practical point of view, since upon dilution with a large volume of biological fluid, micelles with a high critical micelle concentration value may dissociate into monomers and their content may precipitate. ${ }^{11}$ Moreover, polymeric micelles have high kinetic stability due to the presence of multiple sites capable of mediating the hydrophobic interaction between each other and/or hydrophobic drugs. ${ }^{12}$

Important types of polymeric micelle are phospholipid micelles, which are sterically stabilized phospholipid nanomicelles (SSMs) composed of polyethylene glycol and phospholipids (PEGylated phospholipids). PEGylated phospholipids are similar to the amphiphilic copolymers of the A-B type, except that the hydrophobic part is a lipid instead of a hydrophobic polymer block. Acyl chains of lipids form the cargo space of the polymeric micelles that encapsulate or solubilize a variety of poorly soluble therapeutic and diagnostic agents. ${ }^{13}$ Some of the most important PEGylated phospholipids are polyethylene glycol-phosphatidylethanolamine conjugates (PEG-PE), such as polyethylene glycol-distearoyl phosphatidylethanolamine (PEG-DSPE). The molecule consists of hydrophilic flexible PEG that is conjugated to two short hydrophobic fatty acyl groups in the polymer structure, leading PEG-DSPE to form stable micelles. It has also been reported that humans secrete phospholipase A2 (PLA2) that is able to degrade PEGylated phosphatidylethanolamine, thus making them biocompatible and biodegradable drug carriers. ${ }^{14,15}$ PEG-DSPE was first used to prolong the circulating time of liposomes by allowing the lipid part to be incorporated inside the lipid bilayer while the PEG segment attached to the liposomal surface. ${ }^{16,17}$ The PEG segment at the surface has an important role in preventing the rapid uptake by the reticuloendothelial system, enabling liposomes to circulate for a longer time. ${ }^{13}$

Beclomethasone dipropionate (BDP) is a poorly watersoluble drug $(0.16 \mu \mathrm{g} / \mathrm{mL})$ that is frequently used via inhalation in the treatment of asthma/chronic obstructive pulmonary disease. ${ }^{18}$ Since its biological half-life is short, the daily required dose is spread over $3-4$ administrations per day. ${ }^{19}$ Recent pharmacokinetic evidence suggests that BDP is removed from its primary site of action, the lower airways, by mucociliary clearance prior to its dissolution and absorption, and eventually reaches the gastrointestinal tract due to the large particle size of the formulation..$^{20}$ Therefore, extending its residence time with nanosized formulation in the lung could be favorable for maximizing its pharmacodynamic effect and/or decreasing the risks of side effects due to its extra-lung absorption. Therefore, the aim of this study was to formulate loaded SSMs with BDP and evaluate the physicochemical properties and in vitro characteristics of this formulation.

\section{Materials and methods Materials}

BDP was obtained from Sigma-Aldrich Chemie Gmbh (Steinheim, Germany); 1,2-Distearoyl-sn-glycero-3phosphoethanolamine-N-methoxy-poly(ethylene glycol 5000) ( $\mathrm{PEG}_{5000}$-DSPE) was purchased from the NOF Corporation (Tokyo, Japan); high-performance liquid chromatography (HPLC)-grade methanol and chloroform were purchased from Fisher Scientific (New Jersey, Canada, and Leicester, UK, respectively). Phosphate-buffered saline (PBS) tablets were purchased from Sigma-Aldrich.

\section{Drug loading in SSMs}

The BDP-SSMs were prepared using the coprecipitation rehydration method previously described. ${ }^{21}$ Different molar ratios (0.02 to 0.16 ) of BDP and $\mathrm{PEG}_{5000}$-DSPE were dissolved in a methanol:chloroform mixture $(7: 3 \mathrm{v} / \mathrm{v})$. The mixture was sonicated for 2 minutes using a sonicator processor (Bransonic Ultrasonic 8510, Danbury, CT) and then vortexed for 1 minute. The organic solvent was removed to form a dry film by vacuum rotary evaporation (Eyela N-1001S-W, Tokyo, Japan). Any traces of solvent remaining in this film were removed under a vacuum overnight. ${ }^{22}$ The dried films were 
rehydrated with an appropriate volume of PBS and the SSMs were formed by gentle shaking at $40^{\circ} \mathrm{C}$ for 10 minutes. The unsolubilized BDP was removed by filtration using a $0.2 \mu \mathrm{m}$ Minisart microfilter (Sartorius AG, Göttingen, Germany). All of the BDP-SSM dispersions were evaluated to determine the maximum solubilization efficiency by particle size and drug content, as suggested by other researchers. ${ }^{22,23}$ Maximum solubility was defined as the concentration of the solubilized drug that produced a single-sized peak population on photon correlation spectroscopy (PCS), since particles that are not removed by filtration are sterically stabilized particles (SSPs) and would appear as a second signal in the PCS. A blank of SSMs was also prepared following the same method but without the model drug.

\section{Particle size analysis}

Particle size of blank- and BDP-SSMs was evaluated by PCS method using a Malvern Zetasizer 1000HSA (Malvern Instruments, Malvern, UK). The data were analyzed in terms of intensity-weighted distributions. Each reported experimental result was the average of at least nine hydrodynamic diameter values obtained from an analysis of the autocorrelation function accumulated for at least 300 seconds.

\section{BDP content}

Drug content measurements were performed using an ultraviolet-spectrophotometer (U-2000; Hitachi Ltd, Tokyo, Japan) at $240 \mathrm{~nm}$ after diluting the clear aqueous dispersion with methanol $(1: 3 \mathrm{v} / \mathrm{v})$.

\section{Lyophilization of SSMs}

To determine the suitable concentration of $\mathrm{PEG}_{5000}-\mathrm{DSPE}$ for the lyophilization process, $5 \mathrm{mM}$ and $10 \mathrm{mM}$ aqueous dispersions of blank SSMs were prepared and then frozen at $-70^{\circ} \mathrm{C}$, followed by overnight lyophilization using a Labconco 7753501 freeze-dry/shell-freeze system (Labconco Corp, Kansas City, MO). The lyophilized cakes were also examined visually and the particle size and polydispersity index (PI) was determined. The BDP-SSMs with a maximum BDP solubility were lyophilized accordingly for long-term storage. ${ }^{24}$

\section{Zeta potential}

The measurement of zeta potential is a good means of evaluating the stability and the state of polymeric micelle surfaces and detecting any modification after freeze drying. Approximately $0.5 \mathrm{~mL}$ of each of the different formulations was analyzed using a ZEECOM ZC-3000 Zeta Potential Analyzer (Symphotic TII Corporation, Camarillo, CA).

\section{Determination of entrapment efficiency, yield, and drug-loading percentages}

The reconstituted BDP-SSMs were analyzed in terms of entrapment efficiency $(\% \mathrm{EE})$, yield percentage $(\% \mathrm{Y})$, and drug-loading percentage $(\% \mathrm{DL})$ using the following equations: ${ }^{25}$

$$
\% \mathrm{EE}=\left(\frac{a}{b}\right) \times 100
$$

where $(a)$ is the concentration of drug loaded in the SSMs $(\mu \mathrm{g} / \mathrm{mL})$ and $(b)$ is the amount of drug used in the SSM preparation $(\mu \mathrm{g} / \mathrm{mL})$.

$$
\begin{aligned}
& \% \mathrm{Y}=\left(\frac{\text { Weight of the nanoparticles }}{\text { Weight of the feeding polymer and drug }}\right) \times 100 \\
& \% \mathrm{DL}=\left(\frac{\text { Weight of the drug in nanoparticles }}{\text { Weight of the nanoparticles }}\right) \times 100
\end{aligned}
$$

\section{Fourier transform infrared (FTIR) spectroscopy characterization}

FTIR is a good means of evaluating the possible chemical interaction between BDP and $\mathrm{PEG}_{5000}$-DSPE. The FTIR spectra were obtained using an infrared spectrophotometer (Nexus equipped with OMNIC software [v 6.1]; Thermo Nicolet Corp, Madison, WI). The samples, which consisted of approximately 1 to $2 \mathrm{mg}$ of BDP, a physical mixture of BDP and the PEG $_{5000}-\mathrm{DSPE}$, lyophilized loaded SSMs of BDP, and $\mathrm{PEG}_{5000}-\mathrm{DSPE}$ and potassium bromide $(\mathrm{KBr})$ powder, were triturated in an agate mortar with a pestle at a ratio of approximately 1:100 or 2:100 (sample:KBr, [w/w]) and compressed by a compaction force of 16 tons $\mathrm{cm}^{-1}$ and a holding time of 2 minutes to form a disc. The infrared spectra were collected within the range of $400-4000 \mathrm{~cm}^{-1}$.

\section{Differential scanning calorimetry characterization}

To evaluate the physical state of BDP in SSMs, thermal analysis of the BDP-SSMs, the corticosteroid drug (BDP), the PEGylated polymer ( $\left.\mathrm{PEG}_{5000}-\mathrm{DSPE}\right)$, and the physical mixture of the corticosteroid drug and the PEGylated polymer was performed using a Pyris 6 differential scanning calorimeter (DSC) (PerkinElmer, Waltham, MA) as previously described. ${ }^{26}$ 


\section{Transmission electron microscopy (TEM) characterization}

TEM is one of the common methods used to examine nanoscopic polymeric micelles. Morphological examinations of the rehydrated BDP-SSMs were conducted using a TEMx transmission electron microscope (CM12 with Docu version 3.2 Image analysis; Philips, Amsterdam, The Netherlands) as previously described. ${ }^{26}$

\section{Dissolution study}

To determine the sink condition, the solubility of BDP in PBS was measured by placing an excess amount of BDP (300 mg) in $5 \mathrm{~mL}$ PBS (pH 7.4) in a dialysis bag (Spectra/pro, molecular weight cut-off 10,000 KD; Spectrum Chemicals and Laboratory Products, New Brunswick, NJ) placed in a $100 \mathrm{~mL}$ PBS Pyrex ${ }^{\circledR}$ bottle and shaken horizontally at $100 \mathrm{rpm}$ in a thermostatic water bath (WB 22; Memmert $\mathrm{GmbH}$ and $\mathrm{Co} \mathrm{KG}$, Büchenbach, Germany) at $37^{\circ} \mathrm{C} \pm 0.5^{\circ} \mathrm{C}$. Samples of the drug solution were withdrawn from the bottle ( $200 \mu \mathrm{L}$, after 30 hours) and analyzed by a validated HPLC method as previously described. ${ }^{27}$ Due to the low solubility of BDP, Tween ${ }^{\circledR} 80$ (R\&M chemicals, Essex, UK) at a concentration of $0.1 \%(\mathrm{v} / \mathrm{v})$ was added to the dissolution medium to increase the drug solubility and to ensure the sink condition. The resulting equilibrium drug concentration was used to calculate the saturated solubility drug concentration. ${ }^{28}$

For the dissolution study, a dialysis bag method was used as previously described, with minor modification. ${ }^{26}$ A known amount of rehydrated BDP-SSMs or BDP powder (containing the equivalent amount of BDP $[200 \mu \mathrm{g}]$ required for the sink condition) was diluted in $5 \mathrm{~mL}$ of PBS (pH 7.4) and transferred into a dialysis bag. At predetermined time intervals, $200 \mu \mathrm{L}$ of sample was withdrawn from the bottle and analyzed by a validated HPLC method, as described previously. ${ }^{27}$ The kinetics of drug release were examined using the previously described add-in DDSolver program. ${ }^{29}$ Different mathematical kinetic models (zero order, first order, Higuchi, Hixson-Crowell, and Baker-Lonsdale) were used to determine the drug-release kinetics. The criteria for selecting the most appropriate model were based on the goodness of fit (adjusted coefficient of determination, $\mathrm{R}^{2}$ adjusted ) and the Akaike information criterion. ${ }^{30}$

\section{In vitro pulmonary deposition}

Aerodynamic characterization was investigated using a Model 170 Next Generation Impactor ${ }^{\mathrm{TM}}$ (NGI $^{\mathrm{TM}}$; Copley Scientific Ltd, Nottingham, UK) connected to a vacuum pump (HCP4) and Pari LC nebulizer (connected to an air-jet compressor Pari Master type 84G73; Munich, Germany). A flow meter (DFM2; Copley Scientific Ltd, Nottingham, UK) was used to calibrate the airflow through the NGI. Two milliliters of an aqueous preparation containing $0.5 \mathrm{mg}$ of rehydrated BDP-SSMs was nebulized for 15 minutes at a room temperature of $28^{\circ} \mathrm{C}$ and a relative humidity of $65 \%$. The flow rate of $60 \mathrm{~L} / \mathrm{min}$ simulated the mean peak inspiratory flow rate of adult asthmatic patients. ${ }^{27}$ The effective cut-off diameters for the impactor at a flow rate of $60 \mathrm{~L} / \mathrm{min}$ were: $8.06 \mu \mathrm{m}$ (stage 1), $4.46 \mu \mathrm{m}$ (stage 2), $2.82 \mu \mathrm{m}$ (stage 3), $1.66 \mu \mathrm{m}$ (stage 4), $0.94 \mu \mathrm{m}$ (stage 5), $0.55 \mu \mathrm{m}$ (stage 6), and $0.34 \mu \mathrm{m}$ (stage 7). Each stage of the NGI, the induction port, and the inhaler device were rinsed with $10 \mathrm{~mL}$ of the respective HPLC mobile phase and collected for quantitative analysis by HPLC. ${ }^{27}$

The mass median aerodynamic diameter (MMAD) and geometric standard deviation (GSD) were calculated after plotting the cumulative amount of drug under size deposited in each stage of the cascade impactor versus their corresponding aerodynamic diameter as specified by the cascade impactor using log-probability paper. ${ }^{31}$ On this graph, the MMAD of the aerosolized particles is the particle size at which the line crosses the $50 \%$ mark (MMAD $[\mu \mathrm{m}]=\mathrm{D}_{50 \%}$ ).

From a log-normal distribution that is normal with respect to aerodynamic diameter, ${ }^{31}$ the GSD becomes:

$$
\mathrm{GSD}=\sqrt{\left(\frac{84.1 \% \text { undersize }}{15.9 \% \text { undersize }}\right)}
$$

The emitted dose (ED) was determined as the percentage of total amount of drug available for nebulization: ${ }^{27,32}$

$$
\begin{aligned}
\mathrm{ED}= & \left(\frac{\text { Amount of drug recovered in the cascade impactor }}{\text { Amount of drug initially loaded in the device }}\right) \\
& \times 100 \%
\end{aligned}
$$

The fine particle fraction (FPF) was calculated as the total amount of drug deposited on stage 2 or 3 to filter: $:^{27,32,33}$

$$
\begin{aligned}
\mathrm{FPF}=( & \left.\frac{\text { Amount of drug recovered from stage } 2 \text { or } 3 \text { to filter }}{\text { Amount of drug initially loaded in the device }}\right) \\
& \times 100 \%
\end{aligned}
$$

\section{Stability study of SSMs}

\section{Short-term stability of drug-loaded SSMs}

Aqueous dispersions of the final formulations of BDP-SSMs were kept at an ambient temperature of 
$28^{\circ} \mathrm{C} \pm 3{ }^{\circ} \mathrm{C}$ with $70 \% \pm 10 \%$ relative humidity for 3 months. ${ }^{4}$ After a predetermined time interval, the dispersions were filtered through a $0.2 \mu \mathrm{m}$ Minisart microfilter, and the clear aqueous solution was diluted with methanol (drug-loaded SSMs: methanol, 1: $3[\mathrm{v} / \mathrm{v}]$ ). Drug-content analysis was performed using an ultravioletspectrophotometer method.

\section{Long-term stability of drug-loaded SSMs}

To assess the storage stability (long-term stability), lyophilized BDP-SSMs were stored at an ambient temperature of $28^{\circ} \mathrm{C} \pm 3^{\circ} \mathrm{C}$, or at $4^{\circ} \mathrm{C}$ (refrigerator) in a desiccator or at $-20^{\circ} \mathrm{C}$ for 1 year. After a predetermined time interval, the lyophilized BDP-SSMs were rehydrated with distilled water (DW) and the drug content and $Z_{\text {ave }}$ were examined.

The percentage of drug remaining was calculated as below:

$$
\% \text { remain }=\left(\frac{b}{a}\right) \times 100 \%
$$

where $a$ is the initial drug concentration at zero time and $b$ is the drug concentration after a specified time.

\section{Results and discussion Drug loading}

Several techniques have been reported for the preparation of drug-loaded polymeric micelles. Those techniques can be divided to three major categories: (1) the coprecipitation and reconstitution method, (2) the dissolution method, and (3) the dialysis method. In each particular case, the choice of the method is usually determined by the extent of the stability of the model drug in organic or aqueous media and the extent of miscibility of the organic solvent with aqueous media. ${ }^{8}$

In direct dissolution, block copolymer is simply dissolved in an aqueous medium at normal or elevated temperature and the model drug, such as peptides, is added to form the peptides-SSMs. This method is useful for active model drugs, which are unstable in organic solvent but soluble in aqueous media. ${ }^{24,34}$ In the dialysis method, the drug of interest is dissolved in a water-miscible organic solvent (such as dimethyl sulfoxide) and is added to the dried film of the PEG-PE, and drug-loaded micelles are formed upon the removal of the organic solvent by dialysis with water. This method has a greater chance of drug loss during dialysis in the encapsulation process and is more difficult in scale-up production; in addition, the choice of organic solvent affects the particle size and uniformity of the micelles formed. ${ }^{35,36}$ Other researchers have presented distinctions between PEG-b-poly( $\varepsilon$-caprolactone) polymeric micelles prepared using different methods. ${ }^{36}$ They found that the dialysis preparation method did not provide adequate size control, whereas stable assemblies with unimodal size distributions were obtained using the coprecipitation and reconstitution preparation method.

The simplest and most convenient technique for the preparation of drug-loaded PEG-DSPE micelles is the coprecipitation and reconstitution method. This method is utilized for the preparation of many polymeric micelles because of its simplicity and reproducibility. Many examples were found in the literature utilizing this method. ${ }^{37-40}$ Herein, BDP was successfully incorporated into SSMs of $\mathrm{PEG}_{5000}$-DSPE by the coprecipitation and reconstitution method.

\section{Physicochemical properties of BDP-SSMs Maximum solubilization of BDP}

The maximum solubility of BDP in SSMs was assessed with eight different BDP concentrations ranging from 52.1 to $416.8 \mu \mathrm{g} / \mathrm{mL}$ in $5 \mathrm{mM} \mathrm{PEG}_{5000}$-DSPE. All samples $\leq$ $209.65 \pm 7.74 \mu \mathrm{g} / \mathrm{mL}$ (0.08 drug:PEGylated polymer molar ratio) had a single uniform size distribution; above this concentration a second peak was observed and this represents the SSPs (Figure 1).

The maximum solubility value of $\mathrm{BDP}$ in $\mathrm{PEG}_{5000}$-DSPE was at least 1300 times greater than the BDP water solubility $(0.16 \mu \mathrm{g} / \mathrm{mL})$ as previously reported, which indicates the suitability of the carrier to solubilize BDP. ${ }^{18}$ The SSPs were most likely stabilized by the PEG-DSPE and formed aggregates in order to maximize the hydrophobic interactions and hydrogen bonding network with water. ${ }^{22,23} \mathrm{~A}$ similar finding has been reported by Paivarinta et al, who found that BDP formed crystals in dipalmitoylphosphatidylcholine multilamellar liposomes which affected the determined solubilized concentration. ${ }^{41}$

Unlike the SSMs at maximum solubility, SSPs affected the stability of the aqueous dispersion of SSMs because they allowed crystallized nuclei to grow and resulted in a turbid solution after 24 hours at $4^{\circ} \mathrm{C} .42$ This temperature was used as an intermediate temperature between freezing and the ambient temperatures, since efficiently solubilized drug in PEGylated polymer formulations should be stable prior to freeze-drying and also after reconstitution. ${ }^{39}$ 


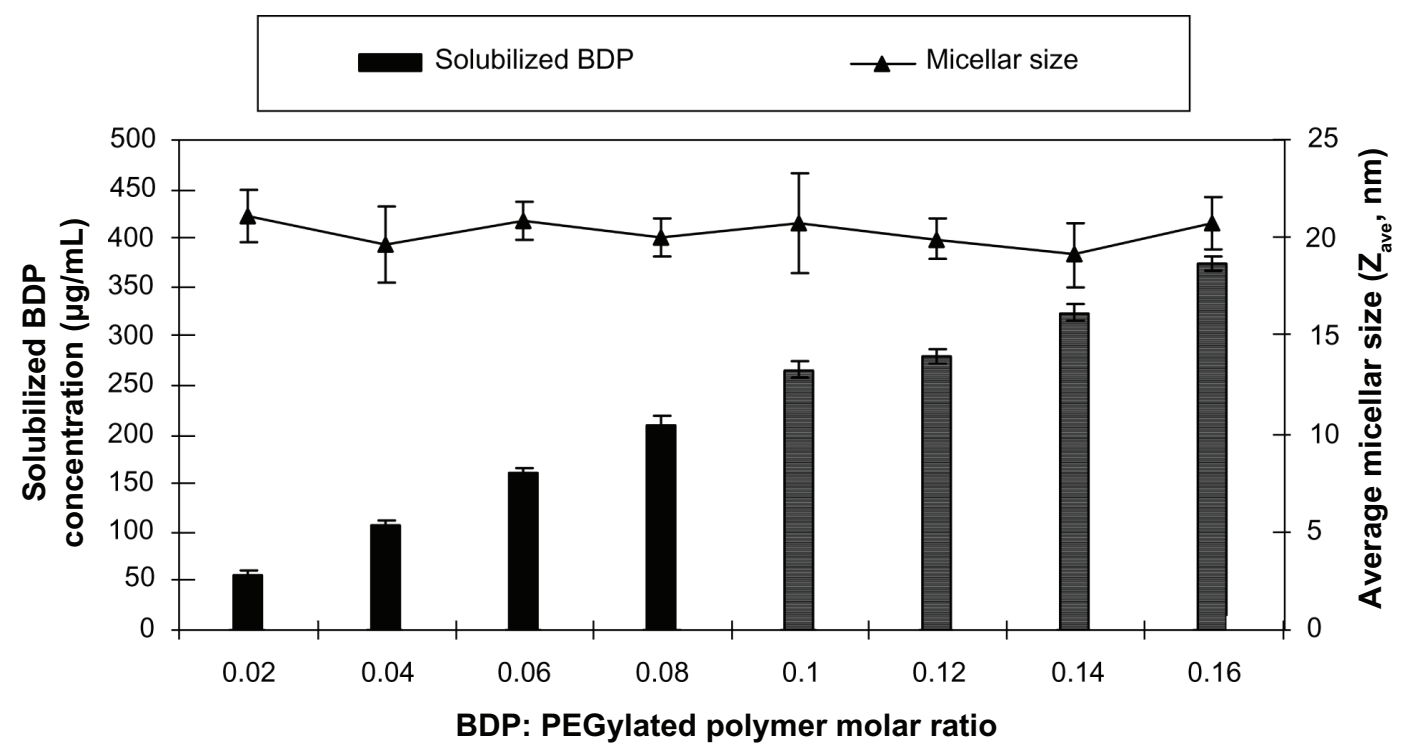

Figure I Effect of the BDP: PEGylated polymer molar ratio on the solubilization of BDP; PEGylated polymer molar concentration kept at 5 mM. Note: Lined bars indicate second population signal in PCS.

Abbreviations: BDP, beclomethasone dipropionate; PCS, photon correlation spectroscopy; PEG, polyethylene glycol.

PEGylated polymer concentration for lyophilization of SSMs

Both 5 and $10 \mathrm{mM}$ of the PEGylated polymer were examined. The results showed that the freeze-dried blankSSM samples had freeze-dried cakes with a fluffy physical appearance (Figure 2A). All freeze-dried samples dissolved upon reconstitution with DW to form clear, colorless solutions. To assess the effect of sample volume, 1 and $0.5 \mathrm{~mL}$ of the blank samples were lyophilized and there were no visual texture differences pronounced for the freeze-dried cakes (Figure 2B).

In addition, there was a decrease in SSM particle sizes with an increase in the PEGylated polymer concentration, even though it was not significant $(P>0.05)$ with narrow PI (Table 1).

Micelle-micelle interactions could occur at a PEGylated polymer concentration of $10 \mathrm{mM}$ due to the closeness of the neighboring micelles; folding of the PEG polymer would take place and result in the formation of a constrained "mushroom" conformation. As a result, smaller particle sizes were obtained, even though this result can be insignificant. At a lower PEGylated polymer concentration of $5 \mathrm{mM}$, the greater distance between SSMs would allow the PEG palisade to form a relaxed "brush" conformation and, hence, larger particle sizes (aggregations) were measured. ${ }^{34}$ Particle surface charge decreased significantly with increasing PEGylated polymer concentration $(P<0.05)$. Yang et al reported that the particle size and surface charge of SSMs depended on the surface density of the PEG block on the lipid core and the concentration of the PEGylated polymers, which was similar to our finding. ${ }^{43}$ Thus, PEGylated polymer could be lyophilized successfully at $5 \mathrm{mM}$ since the hydrophilic PEG polymer in the outer surface (corona) acted as a cryoprotectant and lyoprotectant. ${ }^{23}$

\section{Particle size analysis and zeta potential of BDP-SSMs}

The hydrodynamic particle size, zeta potential, and PI values of BDP-SSMs (at maximum solubilization) and blank SSMs differed insignificantly (Table 1), which indicated that the $\mathrm{PEG}_{5000}$-DSPE copolymer at a concentration of $5 \mathrm{mM}$ was suitable for lyophilization without further addition of any cryoprotectant or lyoprotectant agents. The lyophilized BDPSSMs were white in color, fluffy and cotton-like in appearance, and easily dissolved in DW (Figure 2C). These results indicated that the model drug had no effect on the formation characteristics of SSMs even after the freeze-drying process. The negative surface charge confirmed the stability potential of the SSM formulations ${ }^{44}$ Typically, PEG is conjugated to distearoyl phosphatidylethanolamine (DSPE) via a carbamate linkage that results in a net negative charge on the phosphate moiety. ${ }^{38,45}$ Both particle size and zeta potential values of the BDP-SSMs gave an advantage to the SSM formulations as a pulmonary delivery system. It has been reported that particles of $<260 \mathrm{~nm}$ can escape phagocytosis by macrophages, and that negatively charged particles are arrested in the lungs more efficiently than positively charged molecules. ${ }^{46,47}$ These results make the SSM formulations promising carriers for pulmonary delivery. 

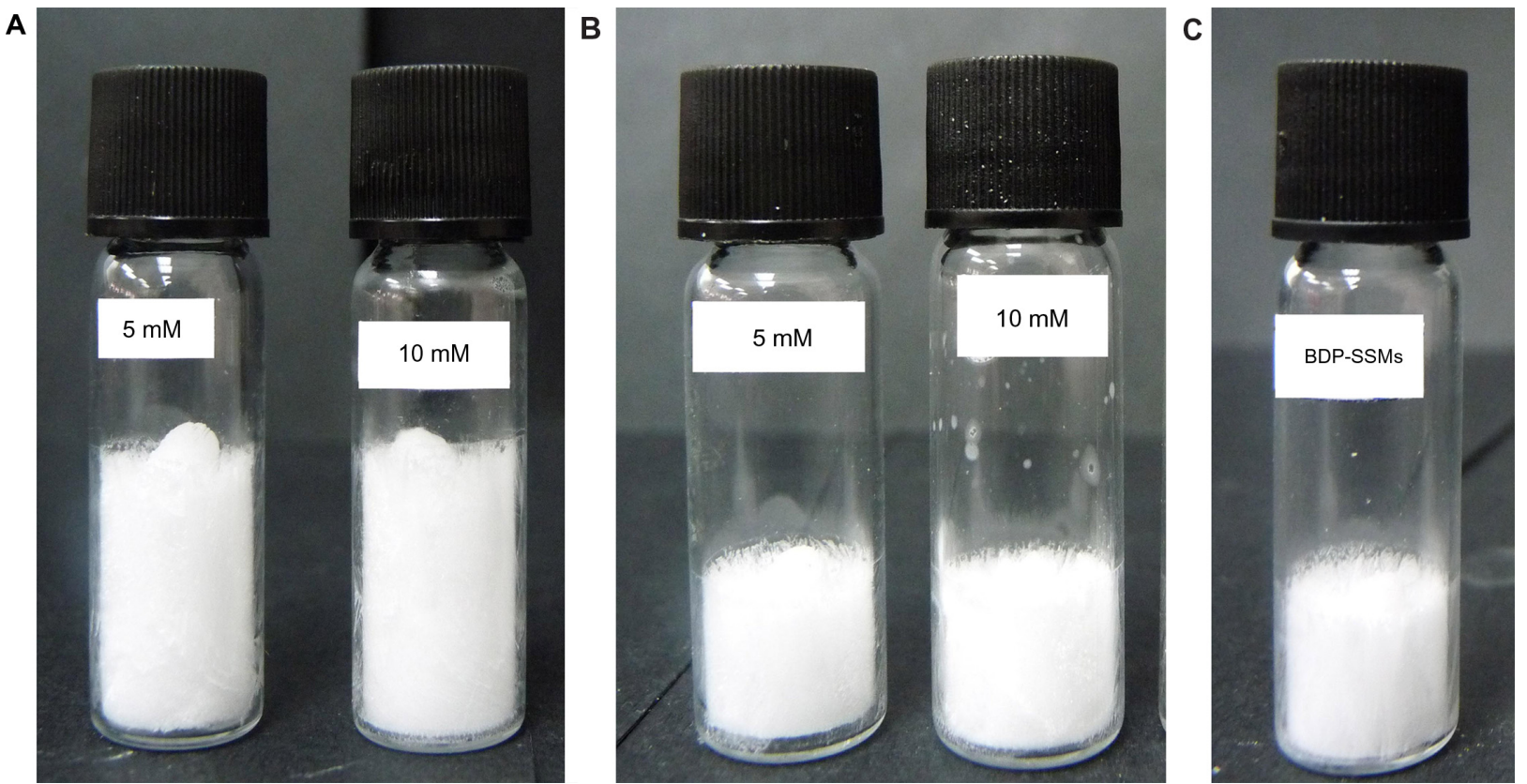

Figure 2 Freeze-dried cakes of SSMs. (A) Blank SSMs at $5 \mathrm{mM}$ and $10 \mathrm{mM}(1 \mathrm{~mL})$; (B) blank SSMs at $5 \mathrm{mM}$ and $10 \mathrm{mM}(0.5 \mathrm{~mL})$; (C) BDP-SSMs.

Abbreviations: BDP-SSMs, sterically stabilized phospholipid nanomicelles containing beclomethasone dipropionate; SSMs, sterically stabilized phospholipid nanomicelles.

\section{Entrapment efficiency, drug loading, and yield percentages of the lyophilized drug-loaded SSMs}

According to the spectrophotometric results and particle size distribution, all BDP molecules were incorporated into the SSMs after lyophilization, which was supported by the insignificant difference found in \%EE pre- $(100.60 \pm 3.71)$ and post-lyophilization $(100.87 \pm 3.59)(P>0.05)$ with no formation of SSPs, as identified by PCS. In addition, a high \%Y $(95.11 \pm 0.38)$ and considerable $\% \mathrm{DL}(0.72 \pm 0.03)$ of the BDPSSM formulations were obtained.

\section{Differential scanning calorimetry}

DSC thermograms of the various samples are shown in Figure 3.

BDP melted with decomposition at approximately $210^{\circ} \mathrm{C} \pm 0.01{ }^{\circ} \mathrm{C}$. The peak for $\mathrm{PEG}_{5000}$-DSPE was $59.91^{\circ} \mathrm{C} \pm 0.04^{\circ} \mathrm{C}$. The peaks of the physical mixtures of BDP and $\mathrm{PEG}_{5000}-\mathrm{DSPE}$ were approximately $201^{\circ} \mathrm{C} \pm 1.52^{\circ} \mathrm{C}$ and $59.64^{\circ} \mathrm{C} \pm 0.57^{\circ} \mathrm{C}$, respectively, with a sharp decrease in the peak intensity for BDP. The lyophilized BDP-SSMs showed only one peak at approximately $58^{\circ} \mathrm{C}$ for $\mathrm{PEG}_{5000^{-}}$ DSPE SSMs with no BDP peak.

These results indicated that the physical mixing of the drug and PEGylated polymer did not affect the block copolymer structure. In contrast, BDP-SSMs caused a slight but significant downward shift of the endothermic peak of the PEGylated polymer, which indicated that there were physical interactions between BDP and the PEGylated polymer. The interactions also suggested that BDP might be molecularly dispersed in the block copolymer matrix. The disappearance of the endothermic peak confirms that BDP changed from the crystalline form to the amorphous state. ${ }^{48}$ Similar results have been reported by other researchers. ${ }^{49,50}$

The disappearance of the endothermic peak corresponding to the melting of BDP at low drug concentrations in the BDP-SSMs was due to their complete miscibility in the molten PEGylated polymer. However, at higher drug ratios (physical mixture), only a partial miscibility was reached

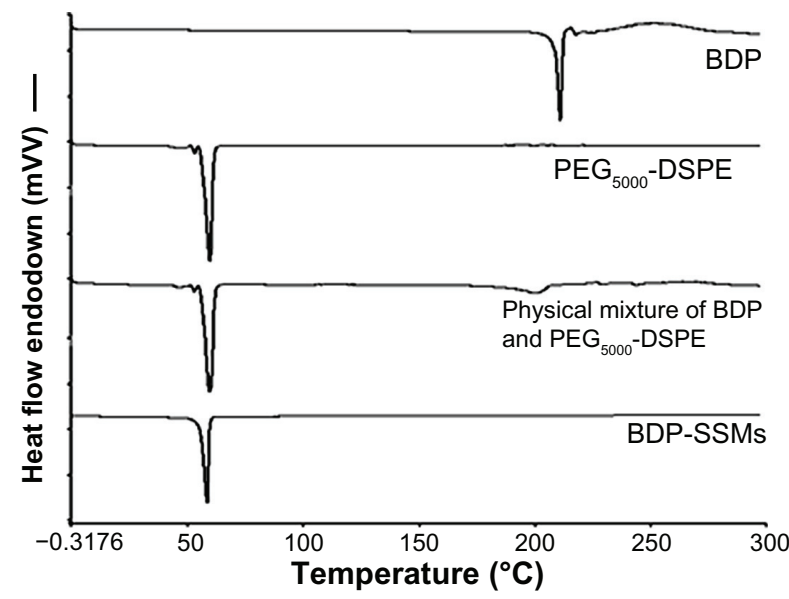

Figure 3 DSC thermograms of BDP, PEG $_{5000}$-DSPE, physical mixture and BDP-SSMs. Abbreviations: BDP-SSMs, sterically stabilized phospholipid nanomicelles containing beclomethasone dipropionate; DSC, differential scanning calorimeter; PEG $_{5000}$-DSPE, I,2-Distearoyl-sn-glycero-3-phosphoethanolamine-N-methoxy-poly (ethylene glycol 5000). 
Table I Particle size, polydispersity index (PI) and zeta potential of SSMs before and after freeze-drying

\begin{tabular}{|c|c|c|c|c|c|c|c|}
\hline \multirow{2}{*}{$\begin{array}{l}\text { PEGylated polymer } \\
\text { and/or BDP-SSMs }\end{array}$} & \multirow[t]{2}{*}{ Concentrations (mM) } & \multicolumn{2}{|c|}{ Particle size (nm) } & \multicolumn{2}{|l|}{$\mathbf{P I}$} & \multicolumn{2}{|c|}{ Zeta potential $(\mathrm{mV})$} \\
\hline & & Before FD & After FD & Before FD & After FD & Before FD & After FD \\
\hline \multirow[t]{2}{*}{$\mathrm{PEG}_{5000}-\mathrm{DSPE}$} & 5 & $20.30 \pm 1.31$ & $20.31 \pm 1.32$ & $0.20 \pm 0.02$ & $0.21 \pm 0.02$ & $-28.70 \pm 2.21$ & $-27.18 \pm 2.50$ \\
\hline & 10 & $17.33 \pm 2.08$ & $18.55 \pm 2.25$ & $0.20 \pm 0.02$ & $0.21 \pm 0.01$ & $-45.51 \pm 2.35$ & $-45.69 \pm 1.63$ \\
\hline BDP: PEG $_{5000}-$ DSPE & $\begin{array}{l}\text { 0.4:5 (Drug: PEGylated } \\
\text { polymer concentration) }\end{array}$ & $19.99 \pm 0.99$ & $19.89 \pm 0.67$ & $0.21 \pm 0.02$ & $0.22 \pm 0.02$ & $-27.70 \pm 2.25$ & $-28.03 \pm 2.05$ \\
\hline
\end{tabular}

Abbreviations: BDP, beclomethasone dipropionate; BDP-SSMs, sterically stabilized phospholipid nanomicelles containing beclomethasone dipropionate; FD, freeze drying; PEG, polyethylene glycol; PEG $_{5000}$-DSPE, I,2-Distearoyl-sn-glycero-3-phosphoethanolamine-N-methoxy-poly(ethylene glycol 5000); SSMs, sterically stabilized phospholipid nanomicelles.

and the drug only began to melt at $198^{\circ} \mathrm{C} \pm 2.00^{\circ} \mathrm{C}$. Similar results have been reported in a study of interaction between $\mathrm{PEG}_{6000}$ and oxazepam..$^{51}$

\section{FTIR}

BDP has conjugated and nonconjugated $\mathrm{C}=\mathrm{O}$ stretching bands. Thus, the bands at 1730 and $1654 \mathrm{~cm}^{-1}$ in the BDP spectrum (Figure 4) corresponded to the nonconjugated acetyl $\mathrm{C}=\mathrm{O}$ stretch and the conjugated stretch bands, respectively. In addition, there was an $(\mathrm{OH})$ vibrational band at $3271 \mathrm{~cm}^{-1}$. Another important band $(\mathrm{C}=\mathrm{C}$ stretching band) for the structure identification of BDP was found at $1614 \mathrm{~cm}^{-1} .^{52}$ The BDP FTIR spectrum showed a $\mathrm{C}=\mathrm{O}$ stretching band for an ester at $1754 \mathrm{~cm}^{-1}$.

The BDP physical mixture with $\mathrm{PEG}_{5000}-\mathrm{DSPE}$ exhibited similar spectra. However, the lyophilized BDP-SSMs exhibited a shift in conjugated $\mathrm{C}=\mathrm{O}$ stretching band from 1654 to $1660 \mathrm{~cm}^{-1}$. This shift was caused by an altered environment of the interatomic $\mathrm{C}=\mathrm{O}$ bonds from the solvation process in the hydrophobic portion of the PEGylated polymer. The formation of intermolecular hydrogen bonds between the $\mathrm{OH}$ group of $\mathrm{BDP}$ and the $\mathrm{C}=\mathrm{O}$ groups of PEGylated polymer could be a possible explanation for this shift. In addition, the $(\mathrm{OH})$ vibration band of BDP-SSMs was shifted, from 3271 to $3288 \mathrm{~cm}^{-1}$. The $\mathrm{C}=\mathrm{O}$ stretching band of the ester was also largely decreased in intensity. The $\mathrm{C}=\mathrm{C}$ stretching band was changed to a broader peak without shifting $\left(1614 \mathrm{~cm}^{-1}\right)$. Hyvönen et al reported similar findings where all bands of $\mathrm{BDP}(\mathrm{OH}, \mathrm{C}=\mathrm{O}$, and $\mathrm{C}=\mathrm{C})$ shifted to higher wave numbers. ${ }^{52}$

No pronounced interactions could be identified between BDP and the PEGylated polymer because no

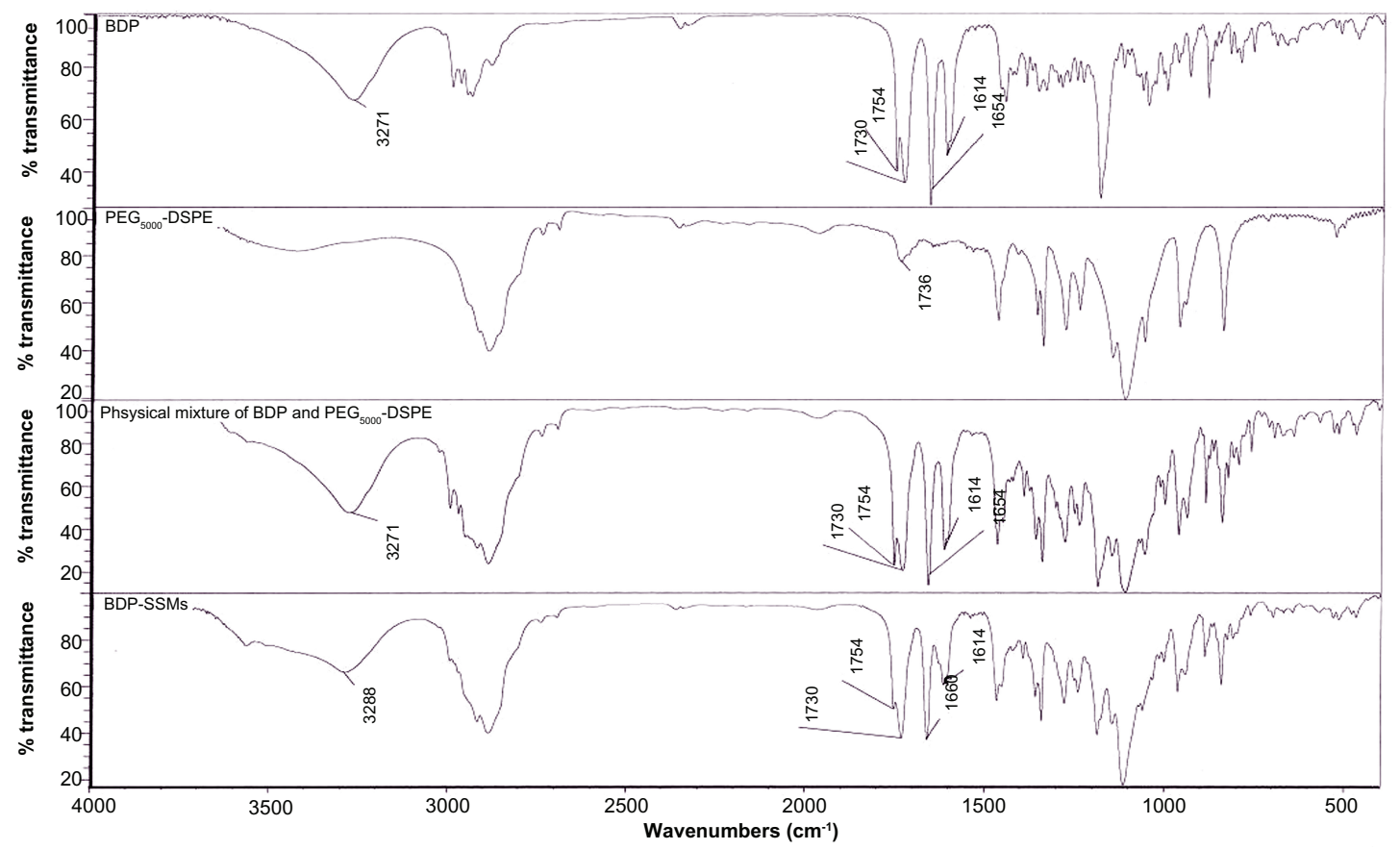

Figure 4 FTIR spectra of BDP, PEG $_{5000}$-DSPE, physical mixture and BDP-SSMs.

Abbreviations: BDP, beclomethasone dipropionate; BDP-SSMs, sterically stabilized phospholipid nanomicelles containing beclomethasone dipropionate; FITR, Fourier transform infrared; PEG $_{5000}$-DSPE, I,2-Distearoyl-sn-glycero-3-phosphoethanolamine-N-methoxy-poly(ethylene glycol 5000). 


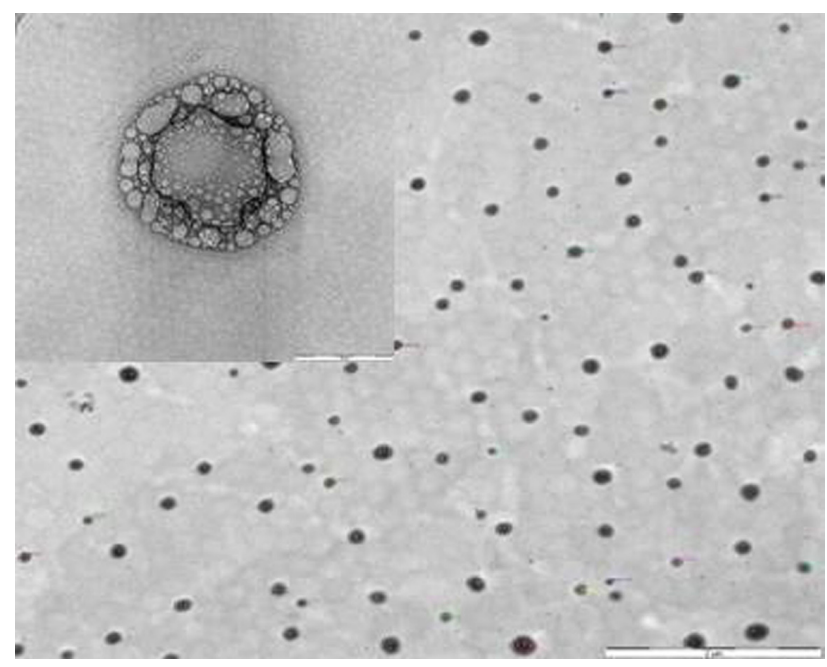

Figure 5 Morphological examinations of BDP-SSMs by transmission electron microscopy.

Note: Scale bar $=2 \mu \mathrm{m}$ and $50 \mathrm{~nm}$.

Abbreviation: BDP-SSMs, sterically stabilized phospholipid nanomicelles containing beclomethasone dipropionate.

significant change or disappearance was evident in the important areas of the spectrum band (conjugated and nonconjugated $\mathrm{C}=\mathrm{O}$ and $\mathrm{C}=\mathrm{C}$ stretching bands), which would indicate that the BDP molecules were in an amorphous state. This result was confirmed by differential scanning calorimetry analysis.

\section{Morphological examination}

Morphological observation of the TEM of BDP-SSMs revealed spherical nanoparticles with bright and dark areas and a core-shell multivesicular appearance with a mean particle size of $104.08 \pm 27.30 \mathrm{~nm}$ (Figure 5). The mean diameters of the blank-SSMs were $100.46 \pm 33.24 \mathrm{~nm}$. These measurements significantly differed from the PCS results. This difference was caused by the tendency of the particles to aggregate as a result of drying the samples, which has also been reported by other researchers. ${ }^{53}$

\section{In vitro dissolution of BDP-SSMs}

The solubility result of BDP in PBS showed a very low value $(0.15 \pm 0.04 \mu \mathrm{g} / \mathrm{mL})$ but the solubility of BDP was markedly increased when Tween $80(0.1 \%$ $\mathrm{v} / \mathrm{v})$ was added to the dissolution medium and reached $14.34 \pm 1.28 \mu \mathrm{g} / \mathrm{mL}$. The addition of a low concentration of surfactants to the dissolution medium ensured the sink condition for some poorly water-soluble compounds. ${ }^{54-57}$ The aqueous solubility of BDP found in this study was in good agreement with the previously reported result of $0.16 \mu \mathrm{g} / \mathrm{mL} .{ }^{18}$ A sink condition is achieved if the final concentration of the drug in the dissolution medium is $<20 \%$ of the saturation solubility of the drug. ${ }^{58}$ The final concentrations of BDP after the complete release in PBS were found to be $<2.87 \mu \mathrm{g} / \mathrm{mL}$ and were in compliance with the sink conditions.

Comparison of the dissolution release profiles of BDP-SSMs with BDP powder at the end of the first 6 hours revealed that $>90 \%$ of BDP powder was released, while $<41 \%$ of BDP was released from BDP-SSMs, with completion of release within 3 days (Figure 6).

The most appropriate drug-release model was selected based on its highest adjusted coefficient of determination $\left(\mathrm{R}^{2}{ }_{\text {adjusted }}\right)$ value and lowest Akaike information criterion. It was found that BDP-SSMs most closely followed the

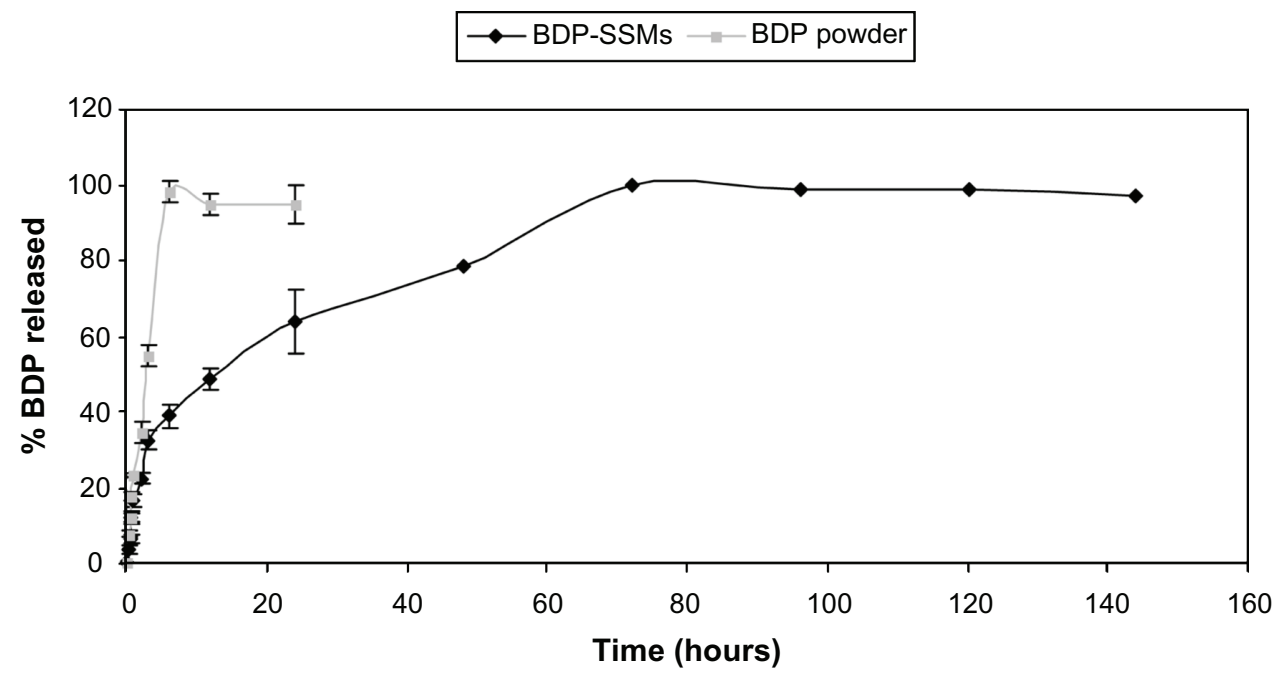

Figure 6 Drug-release profiles of BDP-SSMs and BDP reference powder.

Abbreviations: BDP, beclomethasone dipropionate; BDP-SSMs, sterically stabilized phospholipid nanomicelles containing beclomethasone dipropionate. 
Table 2 Kinetic drug-release values of different BDP formulations

\begin{tabular}{|c|c|c|c|c|c|c|}
\hline \multirow[t]{2}{*}{ Parameters } & \multicolumn{2}{|c|}{$\begin{array}{l}\text { Adjusted coefficient } \\
\text { of determination }\left(\mathbf{R}_{\text {adjusted }}\right)\end{array}$} & \multicolumn{2}{|c|}{$\begin{array}{l}\text { The Akaike information } \\
\text { criterion }\end{array}$} & \multicolumn{2}{|c|}{ Release rate constant } \\
\hline & BDP-SSMs & BDP powder & BDP-SSMs & BDP powder & BDP-SSMs & BDP powder \\
\hline Zero-order kinetic & $0.59 \pm 0.06$ & $0.98 \pm 0.01$ & $93.38 \pm 2.22$ & $35.97 \pm 1.10$ & l & $|7.02 \pm 0.4|$ \\
\hline First-order kinetic & $0.89 \pm 0.03$ & $0.94 \pm 0.01$ & $78.28 \pm 2.56$ & $43.28 \pm 2.31$ & I & 1 \\
\hline Higuchi kinetic & $0.96 \pm 0.01$ & $0.86 \pm 0.02$ & $67.84 \pm 3.72$ & $49.40 \pm 1.57$ & $12.30 \pm 0.52$ & I \\
\hline Baker-Lonsdale model kinetic & $0.98 \pm 0.01$ & I & $60.39 \pm 1.99$ & I & $0.004 \pm 0.00$ & I \\
\hline Hixson-Crowell model kinetic & $0.85 \pm 0.03$ & I & $82.07 \pm 1.92$ & I & I & I \\
\hline
\end{tabular}

Abbreviations: BDP, beclomethasone dipropionate; BDP-SSMs, sterically stabilized phospholipid nanomicelles containing beclomethasone dipropionate.

Baker-Lonsdale model $(P<0.05)$ and further supported the postulation that the release of BDP from SSMs is more consistent with a diffusion mechanism (Higuchi model) $(P<0.05)$ (Table 2) while BDP powder followed the zero-order kinetic.

\section{Aerodynamic characterization of BDP-SSMs}

The distribution of the BDP in the nebulizer, the induction port (throat), and the seven stages of the NGI are clearly demonstrated in Figure 7.

The MMAD, GSD, $\% \mathrm{ED}$, and $\mathrm{FPF}_{<2.8 \text { or } 4.8}$ were $2.83 \pm 0.02 \mu \mathrm{m}, 2.31 \pm 0.08 \mu \mathrm{m}, 59.58 \% \pm 0.85 \%$, and $36.84 \% \pm 0.4 \%$ or $52.56 \% \pm 0.72 \%$, respectively. These results were significantly superior than the results for the Clenil $^{\circledR}$ (a BDP suspension for nebulization, not approved by the US Food and Drug Administration) from Chiesi, Italy, as the MMAD, $\mathrm{FPF}_{<3}, \mathrm{FPF}_{<5}$ were $7.5 \mu \mathrm{m}, 7 \%$, and $23 \%$ respectively. ${ }^{59}$ These significant differences were due to shape and particle size differences. Vaghi et al ${ }^{59}$ found that Clenil contained needle-shaped particles up to $10 \mu \mathrm{m}$ long, while in our study the BDP-SSMs were spherical with a diameter of $14.60 \pm 1.11 \mathrm{~nm}$ on PCS and $100.46 \pm 33.24 \mathrm{~nm}$ on TEM. The nebulized suspension will therefore generate larger aerosol droplets (ie, larger MMAD values) containing a small number of suspension particles, whereas the aerosolized SSM droplets are smaller (with lower MMAD values) and contain many thousands of nanoparticles. ${ }^{48}$ The effect of particle size on the aerodynamic characterization was also reported by other researchers. ${ }^{48,60,61}$ In addition, the effect of the formulation must also be considered. The presence of PEG on the outer layer of the polymeric micelles, which induced a repulsive steric interaction between the particles that could effectively decrease the overall adhesive forces, allowed a more efficient aerosolization, stabilizing the colloidal suspension in the air. ${ }^{61,62}$ These results support the potential of BDP-SSMs made from PEG $_{5000}-\mathrm{DSPE}$ to be

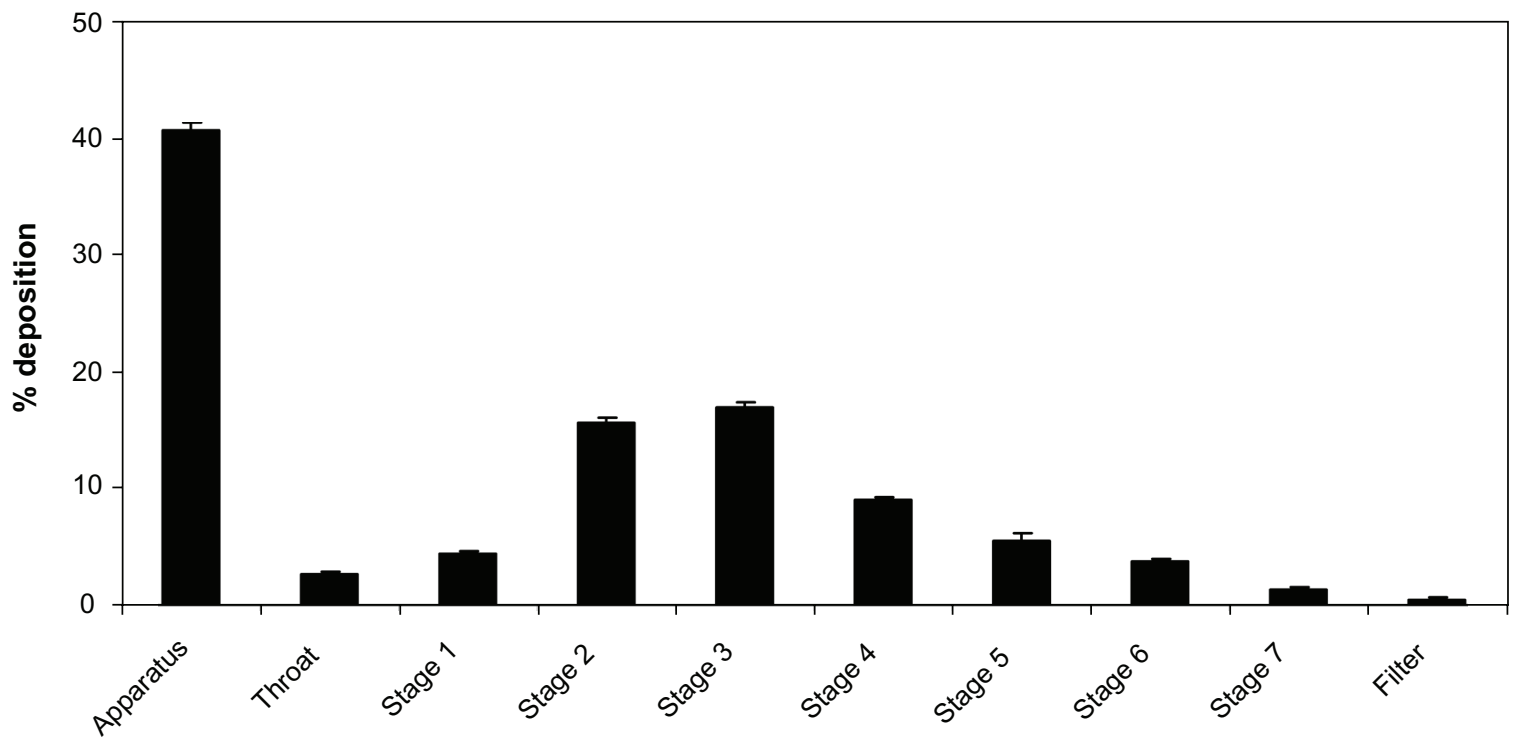

Figure 7 Distribution of aerosolized rehydrated BDP-SSMs using Pari LC nebulizer throughout the Next Generation Impactor ${ }^{\text {TM }}$.

Note: Mean \pm standard deviation, $\mathrm{N}=3$.

Abbreviation: BDP-SSMs, sterically stabilized phospholipid nanomicelles containing beclomethasone dipropionate. 


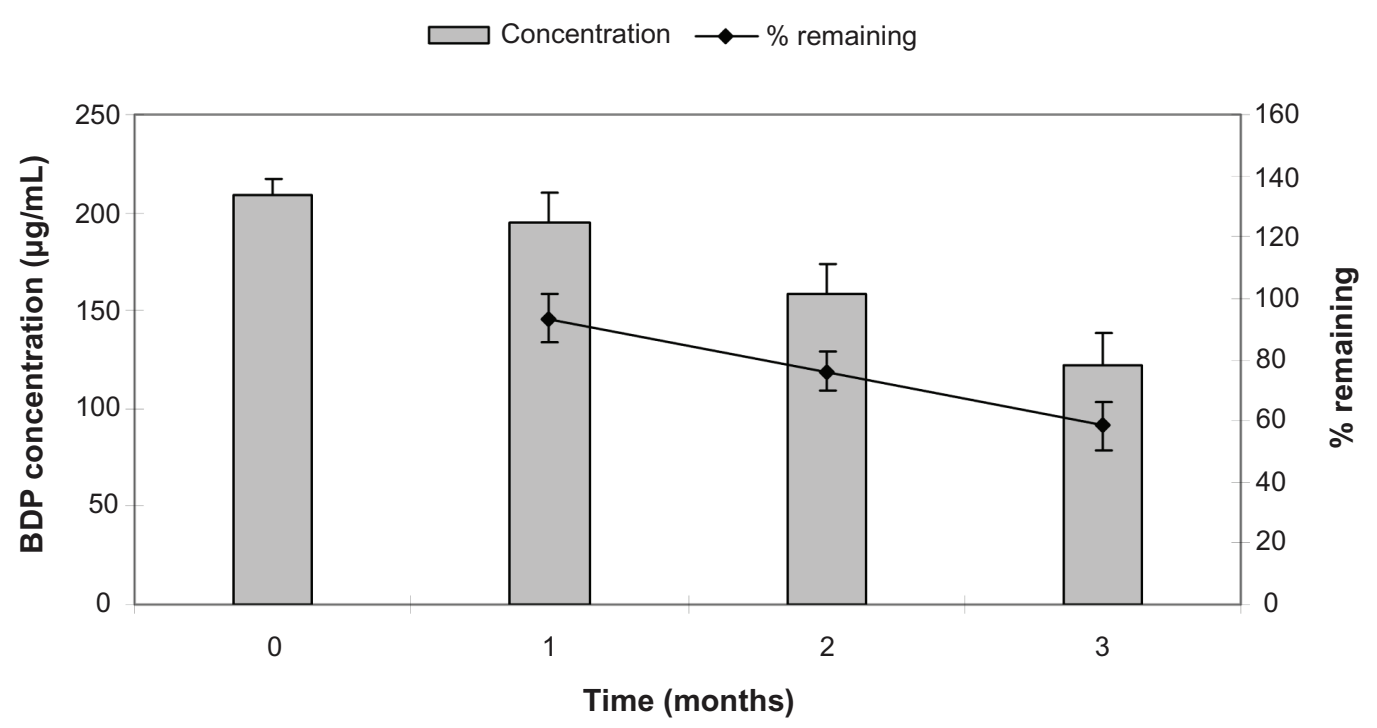

Figure 8 Short-term stability results of aqueous dispersion of BDP-SSMs at $28^{\circ} \mathrm{C} \pm 3^{\circ} \mathrm{C}$ and $70 \% \pm 10 \%$ relative humidity. Abbreviation: BDP-SSMs, sterically stabilized phospholipid nanomicelles containing beclomethasone dipropionate.

useful drug carriers in the treatment of pulmonary-related diseases.

\section{Stability of loaded SSMs}

Temperature is an important factor that affects micellar structure. Micelles are formed at a specific temperature, which is known as the critical micellization temperature (CMT). Values between $25^{\circ} \mathrm{C}$ and $40^{\circ} \mathrm{C}$ are identified as the CMT for most block copolymers. If micelles are refrigerated for a long period of time, the temperature drops to a value lower than the CMT and, as such, polymeric micelles would lose their structure and the solubilized drug would be precipitated out. ${ }^{63}$ For this reason, a short-term stability test was performed at the ambient temperature of $28^{\circ} \mathrm{C} \pm 3^{\circ} \mathrm{C}$ with $70 \% \pm 10 \%$ relative humidity.

There were insignificant differences in the drug concentration (or drug remaining) after a storage period of 1 month. However, after a storage period of 2 or 3 months, the drug concentration (or drug remaining) decreased significantly $(P<0.05)$ (Figure 8$)$. These results indicated that the solubilized corticosteroid drug maintained sufficient stability as drug-loaded SSMs for a period of 1 month.

In general, the stability of SSMs depended on the storage time as well as the degradation tendency of PEGylated micellar structure. As specified by the manufacturer, the commercial

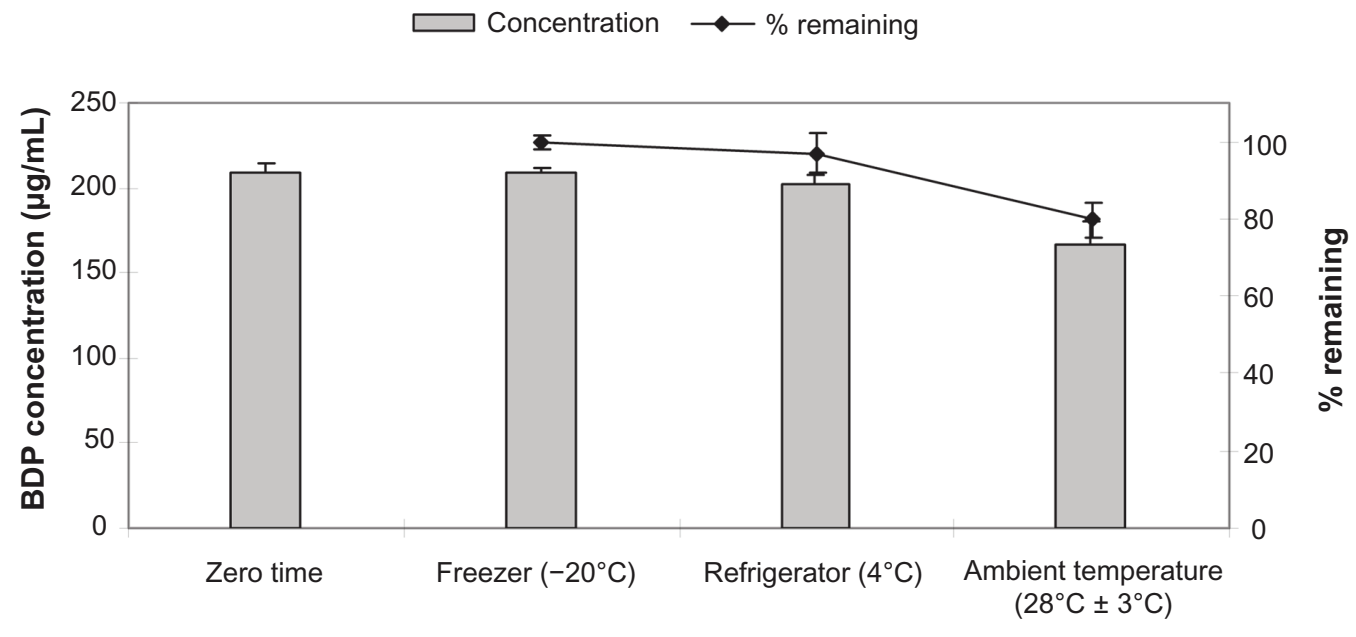

Figure 9 Long-term stability results of lyophilized BDP-SSMs at different storage temperatures for I year.

Abbreviation: BDP-SSMs, sterically stabilized phospholipid nanomicelles containing beclomethasone dipropionate. 
Table 3 Effect of storage temperature on the average particle size and polydispersity index (PI) of the lyophilized BDPSSMs after storing for I year

\begin{tabular}{|c|c|c|c|c|c|c|c|c|}
\hline \multirow[t]{3}{*}{ Formulation/code } & \multicolumn{4}{|c|}{ Particle size $(\mathrm{nm})$} & \multicolumn{4}{|l|}{ PI } \\
\hline & \multirow[t]{2}{*}{ Zero time } & \multicolumn{3}{|l|}{ After I year } & \multirow[t]{2}{*}{ Zero time } & \multicolumn{3}{|c|}{ After I year } \\
\hline & & $-20^{\circ} \mathrm{C}$ & $4^{\circ} \mathrm{C}$ & $28^{\circ} \mathrm{C} \pm 3^{\circ} \mathrm{C}$ & & $-20^{\circ} \mathrm{C}$ & $4^{\circ} \mathrm{C}$ & $28^{\circ} \mathrm{C} \pm 3^{\circ} \mathrm{C}$ \\
\hline BBDP: PEG $_{5000}-\mathrm{DSPE} / \mathrm{F} 45$ & $21.71 \pm 1.90$ & $21.65 \pm 1.32$ & $22.4 I \pm 1.62$ & $26.69 \pm 1.82$ & $0.21 \pm 0.02$ & $0.21 \pm 0.02$ & $0.22 \pm 0.02$ & $0.47 \pm 0.05$ \\
\hline
\end{tabular}

Abbreviations: BDP, beclomethasone dipropionate; BDP-SSMs, sterically stabilized phospholipid nanomicelles containing beclomethasone dipropionate; FD, freeze drying; PEG, polyethylene glycol; PEG $_{5000}$-DSPE, I,2-Distearoyl-sn-glycero-3-phosphoethanolamine-N-methoxy-poly(ethylene glycol 5000); SSMs, sterically stabilized phospholipid nanomicelles.

PEG-DSPE block copolymers are in powder form and must be kept at or below $-20^{\circ} \mathrm{C}$. Thus, keeping these polymeric micelles at ambient temperature $\left(28^{\circ} \mathrm{C} \pm 3^{\circ} \mathrm{C}\right)$ in aqueous solutions was not appropriate with respect to storage stability. Our study confirmed that PEG-DSPE block copolymers were more stable in lyophilized form. These results are in agreement with other reports. Sezgin et al reported that the stability of the polymeric micelles of PEG-DSPE and meso-tetraphenyl porphine (an anticancer agent) decreased by approximately $13 \%$ after 3 months at ambient temperature. ${ }^{4}$

For the long-term stability study, lyophilized formulations were kept at $-20^{\circ} \mathrm{C}, 4^{\circ} \mathrm{C}$, and $28^{\circ} \mathrm{C}$. Even though PEG-DSPE is more stable in its lyophilized form, the storage temperature has a great effect on its final solubilization efficiency. The concentrations of the BDP at time zero and after 12 months at different storage temperatures are shown in Figure 9.

There were insignificant differences between the concentrations of BDP (or drug remaining) at time zero and after storage for 12 months at $-20^{\circ} \mathrm{C}$ and $4^{\circ} \mathrm{C}(P>0.05)$. However, there were significant differences between the concentrations of BDP (or drug remaining) at time zero and after storage for 12 months at the ambient temperature of $28^{\circ} \mathrm{C}(P<0.05)$.

In addition, there were significant differences in the $\mathrm{Z}_{\text {ave }}$ and PI values for the BDP-SSMs when stored at $28^{\circ} \mathrm{C}$ (Table 3).

These results corroborated the previous concentration analysis findings that a change in particle size of the SSMs was more prominent when stored at $28^{\circ} \mathrm{C}$ than at $-20^{\circ} \mathrm{C}$ or $4^{\circ} \mathrm{C}$. Results of the stability studies indicated that when stored at $-20^{\circ} \mathrm{C}$ and $4^{\circ} \mathrm{C}$ the lyophilized BDP-SSMs were sufficiently stable for at least 1 year after preparation.

\section{Conclusion}

BDP-SSMs were successfully prepared by the coprecipitation and reconstitution method. The maximum solubility value of BDP in $\mathrm{PEG}_{5000}$-DSPE was at least 1300 times greater than the BDP water solubility. Maximum solubility should only be measured when the drug-loaded SSMs exhibited a unimodel distribution in PCS. SSPs affected the stability of the SSMs because they provided nuclei for the formation of aggregates, which disrupted the micellar structures. BDP was found to be amorphous by differential scanning calorimetry, and had no chemical interaction with PEGylated polymer according to FTIR results. BDP-SSMs exhibited prolonged dissolution behavior compared with the reference powder. BDP-SSMs successfully aerosolized with significant aerodynamic characterization values. The physicochemical and in vitro evaluation results showed SSM formulations of BDP to be a promising pulmonary delivery system.

\section{Acknowledgment}

This work was supported by the Universiti Sains Malaysia RU Grant 815001. MN Sahib and SA Abdulameer gratefully acknowledge Universiti Sains Malaysia, Penang, Malaysia, for granting them the USM Postgraduate Student Fellowship.

\section{Disclosure}

The authors report no conflicts of interest in this work.

\section{References}

1. Jones M-C, Leroux J-C. Polymeric micelles - a new generation of colloidal drug carriers. Eur J Pharm Biopharm. 1999;48:101-111.

2. Sahib MN, Abdulameer SA, Rasool AA. Design and in viro evaluation of prednisolone tables as a potential colon delivery system. Asian Journal of Pharmaceutical and Clinical Research. 2009;2:84-93.

3. Lipinski CA, Lombardo F, Dominy BW, Feeney PJ. Experimental and computational approaches to estimate solubility and permeability in drug discovery and development settings. Adv Drug Delivery Rev. 2001;46:3-26.

4. Sezgin Z, Yüksel N, Baykara T. Preparation and characterization of polymeric micelles for solubilization of poorly soluble anticancer drugs. Eur J Pharm Biopharm. 2006;64:261-268.

5. Kwon GS, Okano T. Polymeric micelles as new drug carriers. Adv Drug Delivery Rev. 1996;21:107-116.

6. Riess G. Micellization of block copolymers. Prog Polym Sci. 2003;28: 1107-1170.

7. Gao Z, Lukyanov AN, Singhal A, Torchilin VP. Diacyllipid-polymer micelles as nanocarriers for poorly soluble anticancer drugs. Nano Lett. 2002;2:979-982. 
8. Torchilin VP. Structure and design of polymeric surfactant-based drug delivery systems. J Control Release. 2001;73:137-172.

9. Kabanov AV, Batrakova EV, Alakhov VY. Pluronic ${ }^{\circledR}$ block copolymers as novel polymer therapeutics for drug and gene delivery. $J$ Control Release. 2002;82:189-212.

10. Sung Bum L, Teruo O, Kazunori K. Preparation and characterization of the micelle-forming polymeric drug indomethacin-incorporated poly(ethylene oxide)-poly( $\beta$-benzyl L-aspartate) block copolymer micelles. J Pharm Sci. 1996;85:85-90.

11. Torchilin VP. Targeted polymeric micelles for delivery of poorly soluble drugs. Cell Mol Life Sci. 2004;61:2549-2559.

12. Yokoyama M, Sugiyama T, Okano T, Sakurai Y, Naito M, Kataoka K Analysis of micelle formation of an adriamycin-conjugated poly(ethylene glycol)-poly(aspartic acid) block copolymer by gel permeation chromatography. Pharm Res. 1993;10:895-899.

13. Lukyanov AN, Torchilin VP. Micelles from lipid derivatives of watersoluble polymers as delivery systems for poorly soluble drugs. $A d v$ Drug Delivery Rev. 2004;56:1273-1289.

14. Vermehren C, Jørgensen K, Schiffelers R, Frokjaer S. Activity of mammalian secreted phospholipase A2 from inflammatory peritoneal fluid towards PEG-liposomes. Early indications. Int $J$ Pharm. 2001;214:93-98.

15. Davidsen J, Vermehren C, Frokjaer S, Mouritsen OG, Jørgensen K. Drug delivery by phospholipase A2 degradable liposomes. Int J Pharm. 2001;214:67-69.

16. Klibanov AL, Maruyama K, Torchilin VP, Huang L. Amphipathic polyethyleneglycols effectively prolong the circulation time of liposomes. FEBS Lett. 1990;268:235-237.

17. Marques CM. Bunchy Micelles. Langmuir. 1997;13:1430-1433.

18. Sakagami M, Kinoshita W, Sakon K, Sato J, Makino Y. Mucoadhesive beclomethasone microspheres for powder inhalation: their pharmacokinetics and pharmacodynamics evaluation. $J$ Control Release. 2002;80:207-218

19. Barnes P. Inhaled glucocorticoids for asthma. N Engl J Med. 1995; 332:868.

20. Hochhaus G, Mollmann H, Derendorf H, Gonzalez-Rothi R. Pharmacokinetic/pharmacodynamic aspects of aerosol therapy using glucocorticoids as a model. J Clin Pharmacol. 1997;37:881.

21. Sezgin Z, Yuksel N, Baykara T. Investigation of pluronic and PEG-PE micelles as carriers of meso-tetraphenyl porphine for oral administration. Int J Pharm. 2007;332:161-167.

22. Cesur H, Rubinstein I, Pai A, Önyüksel H. Self-associated indisulam in phospholipid-based nanomicelles: a potential nanomedicine for cancer Nanomedicine. 2009;5:178-183.

23. Koo OM, Rubinstein I, Onyuksel H. Camptothecin in sterically stabilized phospholipid micelles: A novel nanomedicine. Nanomedicine. 2005;1:77-84.

24. Önyüksel H, Mohanty PS, Rubinstein I. VIP-grafted sterically stabilized phospholipid nanomicellar 17-allylamino-17-demethoxy geldanamycin: A novel targeted nanomedicine for breast cancer. Int $J$ Pharm. 2009;365:157-161.

25. Zhang L, Hu Y, Jiang X, Yang C, Lu W, Yang YH. Camptothecin derivative-loaded poly(caprolactone-co-lactide)-b-PEG-b-poly(caprolactoneco-lactide) nanoparticles and their biodistribution in mice. $J$ Control Release. 2004;96:135-148.

26. Abdulla J, Tan Y, Darwis Y. Rehydrated lyophilized rifampicin-loaded mpeg-dspe formulations for nebulization. AAPS Pharm Sci Tech. 2010;11:663-671.

27. Sahib MN, Darwis Y, Khiang PK, Fung Tan YT. Aerodynamic characterization of beclomethasone dipropionate from beclate- 50 inhaler $^{\mathrm{B}}$ by HPLC-UV. J Liq Chromatogr Relat Technol. 2011;34:613-621.

28. Davies NM, Feddah MR. A novel method for assessing dissolution of aerosol inhaler products. Int J Pharm. 2003;255:175-187.

29. Zhang Y, Huo M, Zhou J, et al. DDSolver: an add-in program for modeling and comparison of drug dissolution profiles. AAPS J. 2010;12:263-271.
30. Costa F, Sousa J, Pais A, Formosinho S. Comparison of dissolution profiles of ibuprofen pellets. J Control Release. 2003;89:199-212.

31. Wiggins NA. The development of a mathematical approximation technique to determine the mass median aerodynamic diameter (MMAD) and geometric standard deviation (GSD) of drug particles in an inhalation aerosol spray. Drug Dev Ind Pharm. 1991;17:1971-1986.

32. Sahib MN, Darwis Y, Khiang PK, Tan YT. Aerodynamic characterization of marketed inhaler dosage forms: High performance liquid chromatography assay method for the determination of budesonide. Afr J Pharm Pharmaco. 2010;4:878-884.

33. Yamamoto H, Kuno Y, Sugimoto S, Takeuchi H, et al. Surface-modified PLGA nanosphere with chitosan improved pulmonary delivery of calcitonin by mucoadhesion and opening of the intercellular tight junctions. J Control Release. 2005;102:373-381.

34. Lim SB, Rubinstein I, Önyüksel H. Freeze drying of peptide drugs self-associated with long-circulating, biocompatible and biodegradable sterically stabilized phospholipid nanomicelles. Int J Pharm. 2008;356:345-350.

35. Aliabadi HM, Elhasi S, Mahmud A, Gulamhusein R, Mahdipoor P, Lavasanifar A. Encapsulation of hydrophobic drugs in polymeric micelles through co-solvent evaporation: the effect of solvent composition on micellar properties and drug loading. Int J Pharm. 2007;329: $158-165$.

36. Vangeyte P, Gautier S, Jérôme R. About the methods of preparation of poly(ethylene oxide)-b-poly([epsilon]-caprolactone) nanoparticles in water: Analysis by dynamic light scattering. Colloids Surf A. 2004;242:203-211.

37. Krishnadas A, Rubinstein I, Önyüksel H. Sterically stabilized phospholipid mixed micelles: in vitro evaluation as a novel carrier for water-insoluble drugs. Pharm Res. 2003;20:297-302.

38. Wang J, Mongayt DA, Lukyanov AN, Levchenko TS, Torchilin VP. Preparation and in vitro synergistic anticancer effect of Vitamin K3 and 1,8-diazabicyclo[5,4,0]undec-7-ene in poly(ethylene glycol)-diacyllipid micelles. Int J Pharm. 2004;272:129-135.

39. Zhang JX, Hansen CB, Allen TM, Boey A, Boch R. Lipid-derivatized poly(ethylene glycol) micellar formulations of benzoporphyrin derivatives. J Control Release. 2003;86:323-338.

40. Ashok B, Arleth L, Hjelm RP, Rubinstein I, Onyüksel H. In vitro characterization of PEGylated phospholipid micelles for improved drug solubilization: Effects of PEG chain length and PC incorporation. $J$ Pharm Sci. 2004;93:2476-2487.

41. Paivarinta JT, Poso AT, Hotokka M, Muttonen E. Aggregation and solvation of steroid molecules in different solvents. Cryst Growth Des. 2002;2:121-126.

42. Abdelwahed W, Degobert G, Stainmesse S, Fessi H. Freeze-drying of nanoparticles: Formulation, process and storage considerations. $A d v$ Drug Delivery Rev. 2006;58:1688-1713.

43. Yang ZL, Li XR, Yang KW, Liu Y. Amphotericin B-loaded poly(ethylene glycol)-poly(lactide) micelles: Preparation, freeze-drying, and in vitro release. J Biomed Mater Res A. 2008;85A:539-546.

44. Gill KK, Nazzal S, Kaddoumi A. Paclitaxel loaded PEG5000-DSPE micelles as pulmonary delivery platform: Formulation characterization, tissue distribution, plasma pharmacokinetics, and toxicological evaluation. Eur J Pharm Biopharm. 2011;79:276-284.

45. Webb MS, Saxon D, Wong FM, et al. Comparison of different hydrophobic anchors conjugated to poly(ethylene glycol): effects on the pharmacokinetics of liposomal vincristine. Biochim Biophys Acta Biomembr. 1998;1372:272-282.

46. Yang W, Peters JI, Williams Iii RO. Inhaled nanoparticles - a current review. Int J Pharm. 2008;356:239-247.

47. Fidler I, Raz A, Fogler W, Kirsh R, et al. Design of liposomes to improve delivery of macrophage-augmenting agents to alveolar macrophages. Cancer Res. 1980;40:4460.

48. Ostrander K, Bosch H, Bondanza D. An in-vitro assessment of a NanoCrystal beclomethasone dipropionate colloidal dispersion via ultrasonic nebulization. Eur J Pharm Biopharm. 1999;48:207-215. 
49. Darwis Y, Kellaway IW. Nebulisation of rehydrated freeze-dried beclomethasone dipropionate liposomes. Int J Pharm. 2001;215:113-121.

50. Zhang X, Jackson JK, Burt HM. Development of amphiphilic diblock copolymers as micellar carriers of taxol. Int J Pharm. 1996;132: 195-206.

51. Arias MJ, Moyano JR, Ginés JM. Study by DSC and HSM of the oxazepam-PEG 6000 and oxazepam-D-mannitol systems: Application to the preparation of solid dispersions. Thermochim Acta. 1998;321:33-41.

52. Hyvönen S, Peltonen L, Karjalainen M, Hirvonen J. Effect of nanoprecipitation on the physicochemical properties of low molecular weight poly(l-lactic acid) nanoparticles loaded with salbutamol sulphate and beclomethasone dipropionate. Int J Pharm. 2005;295: 269-281.

53. Falamarzian A, Lavasanifar A. Optimization of the hydrophobic domain in poly(ethylene oxide)-poly([var epsilon]-caprolactone) based nano-carriers for the solubilization and delivery of Amphotericin B. Colloids Surf B Biointerfaces. 2010;81:313-320.

54. Bajerski L, Rossi RC, Dias CL, Bergold AM, Fröehlich PE. Development and validation of a discriminating in vitro dissolution method for a poorly soluble drug, olmesartan medoxomil: comparison between commercial tablets. AAPS Pharm Sci Tech. 2010;11:637-644.

55. Brown CK, Chokshi HP, Nickerson B, Reed RA, Rohrs BR, Shah PA. Dissolution testing of poorly soluble compounds. Pharmaceutical Technolog. 2004;28:56-43.

56. Rohrs BR. Dissolution method development for poorly soluble compounds. Dissolution Technologies. 2001;8:6-12.
57. Shah VP, Konecny JJ, Everett RL, McCullough B, Noorizadeh AC, Skelly JP. In vitro dissolution profile of water-insoluble drug dosage forms in the presence of surfactants. Pharm Res. 1989;6:612-618.

58. Muthu M, Singh S. Poly (D, L-Lactide) nanosuspensions of risperidone for parenteral delivery: formulation and in-vitro evaluation. Curr Drug Deliv. 2009;6:62-68.

59. Vaghi A, Berg E, Liljedahl S, Svensson JO. In vitro comparison of nebulised budesonide (Pulmicort Respules ${ }^{\circledR}$ ) and beclomethasone dipropionate (Clenil ${ }^{\circledR}$ per Aerosol). Pulm Pharmacol Ther. 2005;18:151-153.

60. Amani A, York P, Chrystyn H, Clark B. Evaluation of a Nanoemulsion-Based Formulation for Respiratory Delivery of Budesonide by Nebulizers. AAPS Pharm Sci Tech. 2010;11:1147-1151.

61. Dailey LA, Schmehl T, Gessler T, et al. Nebulization of biodegradable nanoparticles: impact of nebulizer technology and nanoparticle characteristics on aerosol features. $J$ Control Release. 2003;86:131-144.

62. Coombes A, Tasker S, Lindblad M, et al. Biodegradable polymeric microparticles for drug delivery and vaccine formulation: the surface attachment of hydrophilic species using the concept of poly (ethylene glycol) anchoring segments. Biomaterials. 1997;18:1153-1161.

63. Kabanov AV, Alakhov VY. Pluronic ${ }^{\circledR}$ block copolymers in drug delivery: From micellar nanocontainers to biological response modifiers. Crit Rev Ther Drug Carrier Syst. 2002;19:1-73.
Drug Design, Development and Therapy

\section{Publish your work in this journal}

Drug Design, Development and Therapy is an international, peerreviewed open-access journal that spans the spectrum of drug design and development through to clinical applications. Clinical outcomes, patient safety, and programs for the development and effective, safe, and sustained use of medicines are a feature of the journal, which

\section{Dovepress}

has also been accepted for indexing on PubMed Central. The manuscript management system is completely online and includes a very quick and fair peer-review system, which is all easy to use. Visit http://www.dovepress.com/testimonials.php to read real quotes from published authors.

Submit your manuscript here: http://www.dovepress.com/drug-design-development-and-therapy-journal 